\title{
Influence of fish swimming on the flow pattern of circular tanks
}

\author{
Ingrid Masaló*, Joan Oca \\ Departament d'Enginyeria Agroalimentària i Biotecnologia, Universitat Politècnica de Catalunya (BarcelonaTech), C/Esteve Terrades 8 , 08860 Castelldefels, Spain
}

\section{A R T I C L E IN F O}

Article history:

Received 30 March 2016

Received in revised form 14 June 2016

Accepted 4 July 2016

Available online $\mathrm{xxx}$

Keywords:

Fish-tank hydrodynamics

Tank resistance coefficient

Turbulent viscosity

Fish swimming

\section{A B S T R A C T}

The effect of swimming fish on the average velocity and velocity profile of a circular tank was studied. Working with different inlet diameters and flow rates, nine different impulse forces (configurations) were evaluated. Each configuration was tested with and without fish, and the effects of two different fish sizes were compared.

The velocity profiles in experiments with fish presented a considerable reduction in velocity in the centre of the tank near the outlet, which was a consequence of the increase in the kinematic eddy viscosity due to the turbulence introduced by fish swimming. A flattening of the angular velocity profile was observed in the central area of the tank, which had a radius of about $0.3 \mathrm{~m}$ ( $18 \%$ of the total volume of the tank).

A previous model proposed by Oca and Masaló (2013) was modified in order to better describe the distribution of velocities in the central volume of a tank with swimming fish. The proposed modification was based on Burgers' proposal for a bathtub vortex, which implies the determination of the parameter $\left(1-\mathrm{e}^{-\alpha r^{2}}\right)$, where $r$ is the radius and the $\alpha$ values were experimentally obtained for each tank configuration, in which they increased with the impulse force.

The average velocities in the tank were proportional to the square root of the impulse force in experiments with and without fish. Experiments with fish presented lower average velocities, which imply higher tank resistance coefficients. At similar stocking densities $\left(14.6 \mathrm{~kg} / \mathrm{m}^{3}\right)$, the increase in the tank resistance coefficients obtained with small fish sizes $(154 \mathrm{~g})$ were slightly higher than those obtained with bigger fish sizes $(330 \mathrm{~g})$.

C) 2016 Published by Elsevier Ltd.

\section{Introduction}

Circular tank geometry is very common in aquaculture. It provides more stable flow patterns, a more homogeneous distribution of dissolved oxygen and metabolites, and better self-cleaning features. Indeed, this tank geometry allows higher velocities than rectangular tanks, thanks to the rotating characteristics of the flow (Oca et al., 2004).

Water inlet design and the direction of the flow injection are the main parameters that define the velocity distribution and flow pattern in circular tanks, which has been widely studied without fish (Larmoyeux et al., 1973; Klapsis and Burley, 1984; Burley and Klapsis, 1985; Tvinnereim, 1988; Oca and Masaló, 2007, 2013).

Tvinnereim and Skybakmoen (1989), working with a tank with a circular flow pattern, pointed out that water velocity is controlled by the inlet impulse force $\left(F_{i}\right.$, Eq. (1)).

$$
F_{i}=\rho \mathrm{Q}\left(V_{i n}-V_{a v g}\right)
$$

where $\rho$ is the water density, $Q$ the injected water flow rate, and $V_{\text {in }}$ and $V_{\text {avg }}$ are, respectively, the jet inlet velocity and the average circulating velocity of water in the tank.

\footnotetext{
* Corresponding author.

Email address: ingrid.masalo@upc.edu (I. Masaló)
}

The inlet velocity $\left(V_{i n}\right)$ is commonly much higher than the average velocity $\left(V_{\text {avg }}\right)$ and Eq. (1) can be expressed as Eq. (2):

$$
F_{i}=\rho \mathrm{Q} V_{i n}
$$

Oca and Masaló (2007), working with small scale laboratory models with rotating flow patterns (circular and rectangular tanks), defined the tank resistance coefficient $\left(C_{t}\right.$, Eq. (3)). $C_{t}$ allows characterizing the resistance to water circulation offered by a specific tank configuration with a rotating flow pattern.

$$
C_{t}=\frac{2 Q V_{i n}}{A\left(V_{a v g}\right)^{2}}
$$

where $A$ is the wet area.

From Eq. (3) the relationship between $V_{a v g}$ and $F_{i}$ can be determined (Eq. (4)).

$$
V_{a v g}=\sqrt{2 /\left(\rho A C_{t}\right)} \sqrt{F_{i}}
$$


Taking the constant value $\left(2 /\left(\rho A C_{t}\right)\right)^{0.5}=K$, we can write:

$V_{a v g}=K \sqrt{F_{i}}$

From Eqs. (4) and (5), it is observed that the average velocity is proportional to the square root of the impulse force.

In addition to the average velocity, the distribution of velocities is also important, since a velocity gradient from the outer to the inner area of the tank is found in circular tanks. This velocity gradient results in heterogeneity of conditions, which promotes less efficient use of the available space. Oca and Masaló (2013) developed a model to determine the velocity profiles in circular tanks without fish. They determine the velocity at a certain radius of a tank from angular momentum per unit mass $(\beta)$ around the central axis and next to the wall (see Section 2.1).

In a tank with fish, where turbulence due to fish movement is introduced (Masaló et al., 2008; Plew et al., 2015) and mixing is enhanced (Rasmussen et al., 2005; Lunger et al., 2006) velocity profile is changed, and also resistance to water circulation. Recent studies pointed out that average velocity is reduced and turbulence is increased in circular tanks with fish (Plew et al., 2015), and as a consequence high resistance to water circulation and changes in velocity distributions were observed.

The objective of this work is to determine how fish affect velocity distribution in a circular tank and, to study the effect of fish size. In a second step, we take as a reference the model proposed by Oca and Masaló (2013) for circular tanks without fish, and adapt it to consider the fish effect.

\section{Material and methods}

\subsection{Velocity profile: analytical model}

Oca and Masaló (2013) proposed a model to estimate the distribution of velocities in circular tanks by determining the angular momentum per unit mass $(\beta=V \times r)$ next to the tank wall and around the central axis. These authors found that the distribution of $\beta$ along a tank radius fits very well to the exponential function shown in Eq. (6), where the parameters $c$ and $k$ must be experimentally determined by linear regression between $\log \beta$ and $r$.

$$
\beta=c e^{k r}
$$

Taking $r=0$ in Eq. (6), the angular momentum per unit mass in the tank center $\left(\beta_{0}\right.$ at $\left.r=0\right)$ will be equal to $c\left(\beta_{0}=c\right)$; and near the wall $\left(\beta_{w}\right.$ at $\left.r=R\right)$, the angular momentum will be:

$$
\beta_{w}=\beta_{0} e^{k R}
$$

The velocity at a certain radius could be calculated as shown in Eq. (8).

$$
V=\frac{1}{r} \beta_{0}^{\left(1-\frac{r}{R}\right)} \beta_{w}^{\left(\frac{r}{R}\right)}
$$

where: $\beta_{0}$ and $\beta_{w}$ are the angular momentum per unit mass around the central axis, and next to the wall, respectively, $R$ is the tank radius, and $r$ is the distance from a point to the tank center (Fig. 1).
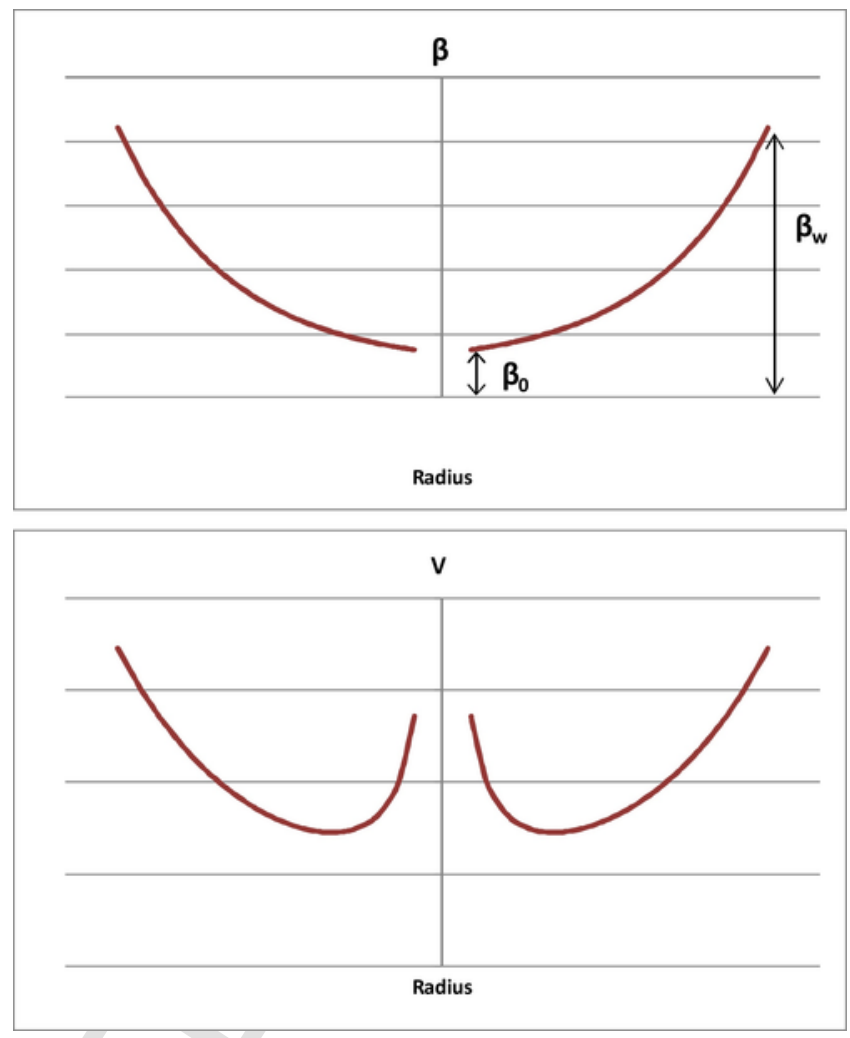

Fig. 1. Angular momentum per unit mass $(\beta)$ and tangential velocity $(V)$ distributions in a tank diameter.

According to Eq. (8), the velocity next to the tank wall $(r=R)$ is determined by $\beta_{w}$; and when $r$ decreases, $\beta_{0}$ becomes more important in determining velocity.

Oca and Masaló (2013) found experimentally that there is a linear relationship between $\beta_{w}$ and the square root of $F_{i}$ (Eq. (9)).

$$
\beta_{w}=m\left[\frac{F_{i}}{H}\right]^{0.5}
$$

with $m$ being the constant of proportionality between $\beta_{w}$ and $\left(\mathrm{F}_{\mathrm{i}} / \mathrm{H}\right)^{0.5}$, which is determined by linear regression, and $H$ the water height.

A linear relationship was also found between $\beta_{0}$ and flow rate $(Q)$ (Eq. (10)).

$$
\beta_{0}=n Q-p
$$

$n$ and $p$ are determined by linear regression between $\beta_{0}$ and $Q$.

$m, n$ and $p$ are the model tuning parameters. When these tuning parameters are known for a specific tank, $\beta_{0}$ and $\beta_{w}$ can be obtained for any $F_{i}$ and $Q$; and then $V$ can be calculated at different distances from the tank center according to Eq. (8). Thus, the velocity profile is drawn.

Nevertheless, Eq. (8) cannot be applied to the center of the tank $(r=0)$, since $V$ would tend to infinity. This phenomena has been analyzed in depth via the so-called "bathtub vortex", which describes the vortex around a central outlet where no impulse force is introduced (e.g., Andersen et al., 2006). In a bathtub vortex two flow regimes are described (Yukimoto et al., 2010): Regime I, outside the region where 
friction losses dominate $\left(r>r_{c}\right)$, where a free vortex is observed and $\beta$ takes a constant value $C$, and velocity is determined by $V=C / r$; Regime II: inside the region where friction losses dominate $\left(r<r_{c}\right)$, where velocity is proportional to radius, and a forced vortex appear. In the forced vortex, the angular velocity $(\omega)$, defined as $\omega=V / r$, is constant and the water rotates like a solid body.

Different approximations to describe the distribution of velocities in the bathtub vortex have been used; e.g., the Rankine combined vortex (Rankine, 1858) or the Burgers vortex (Burgers, 1948) (Fig. 2).

Burgers' model gives a distribution of tangential velocities in a vortex to describe the transition between the zone where the angular velocity is not constant (outside the forced vortex; $r>r_{c}$ ) and the zone where the angular velocity is constant (forced vortex; $r<r_{c}$ ), and it
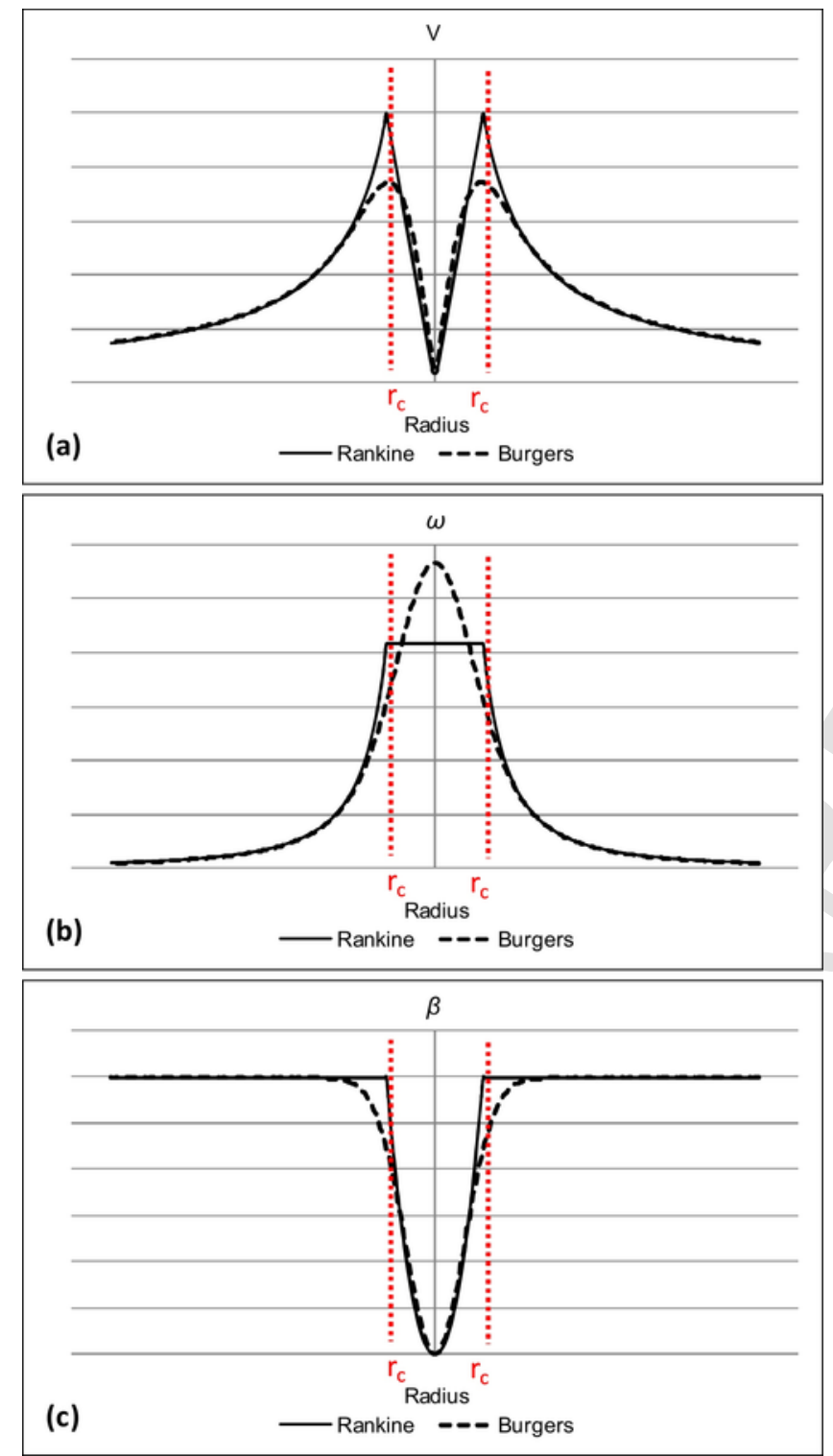

Fig. 2. Distribution of (a) tangential velocities $V$, (b) angular velocities $\omega$ and (c) angular momentum per unit mass $\beta$ that were obtained with the Rankine combined vortex model (continuous line) and with the Burgers model (dashed line). The vertical dashed line (red) indicates the distance from the water outlet where the forced vortex $\left(r<r_{c}\right)$ is observed. (For interpretation of the references to color in this figure legend, the reader is referred to the web version of this article.) does so by following the mathematical form:

$$
V=\frac{\mathrm{C}}{r}\left(1-e^{-\alpha r^{2}}\right)
$$

where $\alpha$ takes lower values when the viscosity increases

In Eq. (11), the first term determines the velocity distribution outside the central forced vortex, and this term is multiplied by $\left(1-\mathrm{e}^{-\alpha r^{2}}\right)$. For high $r$ values, the term $\left(1-\mathrm{e}^{-\alpha r^{2}}\right)$ will tend to 1 (showing a small effect on $V$ ), but the term will tend to 0 when $r$ is close to the tank center and will have stronger influence on $V$.

In a tank without fish, the central forced vortex area of influence is very small and is frequently not detected because of its lower radius of influence (Oca and Masaló, 2013). Nevertheless in a tank with fish, where higher turbulence is detected, turbulent viscosity will contribute to increasing the relative importance of friction forces and to enlarging the area affected by the central forced vortex.

In this work the Oca and Masaló's model is adapted for a tank with fish, where friction forces will be more important and can modify $\beta_{0}$ and $\beta_{w}$. They can also enlarge the central area that is influenced by these friction losses, where velocities could not be described by Eq. (8).

\subsection{Experimental tests}

Experiments were carried out in a circular tank in the facilities of the Escola Superior d'Agricultura de Barcelona at the Universitat Politècnica de Catalunya-BarcelonaTech.

Experiments were developed in a circular tank (fiberglass, $144 \mathrm{~cm}$ diameter and $30 \mathrm{~cm}$ water depth) using five flow rates and three inlet diameters (Table 1) to provide different impulse forces (see Eq. (2)). Each experiment was conducted with and without fish. Two populations of sea bass (Dicentrarchus labrax) with two different individual weights were used (Table 2).

\subsubsection{Flow circulation and fish culture conditions}

Flow rate was adjusted using rotameters, and water was injected always through a single pipe tangential to the wall at a mid-depth water level. Water left the tank through an outlet placed in the middle-bottom of the tank. The outlet was composed of a pipe (PVC, $75 \mathrm{~mm}$ diameter) with slots (Fig. 3). Water leaving the tank was conducted to an overflowing pipe placed next to the tank, which allowed maintaining a $30 \mathrm{~cm}$ water depth. A thin boundary layer was expected around the pipe, nevertheless, Oca and Masaló (2013) not detect it because it

Table 1

Configurations tested in the experiments with and without fish. Flow rate $(Q)$ in $\mathrm{L} / \mathrm{h}$ Inlet diameter $\left(D_{i}\right)$ in $\mathrm{mm}$; Impulse force $\left(F_{i}\right.$; Eq. $\left.(2)\right)$ in $\mathrm{N}$; Inlet velocity $\left(V_{\text {in }}\right)$ in $\mathrm{m} / \mathrm{s}$.

\begin{tabular}{lll}
\hline$D i(\mathrm{~mm})$ & & 32 \\
\hline 13 & 20.5 & - \\
\hline $\mathrm{Q} 550-\mathrm{V}_{\text {in }} 1.152-\mathrm{F}_{\mathrm{i}}$ & - & - \\
0.183 & & \\
$\mathrm{Q} 800-\mathrm{V}_{\text {in }} 1.675-$ & $\mathrm{Q} 800-\mathrm{V}_{\text {in }} 0.674-\mathrm{Fi}$ & \\
$\mathrm{F}_{\mathrm{i}} 0.387$ & 0.156 & $\mathrm{Q} 1000-\mathrm{V}_{\text {in }} 0.346-\mathrm{Fi}$ \\
- & $\mathrm{Q} 1000-\mathrm{V}_{\text {in }} 0.842-\mathrm{Fi}$ & 0.100 \\
& 0.243 & $\mathrm{Q} 1500-\mathrm{V}_{\text {in }} 0.519-\mathrm{Fi}$ \\
- & $\mathrm{Q} 1500-\mathrm{V}_{\text {in }} 1.263-\mathrm{Fi}$ & 0.225 \\
& 0.546 & $\mathrm{Q} 1900-\mathrm{V}_{\text {in }} 0.657-\mathrm{Fi}$ \\
- & $\mathrm{Q} 1900-\mathrm{V}_{\text {in }} 1.600-\mathrm{Fi}$ & 0.360 \\
\hline
\end{tabular}


Table 2

Individual weight $(\mathrm{g})$, total body length $(\mathrm{cm})$, stocking density $\left(\mathrm{kg} / \mathrm{m}^{3}\right)$, and number of fish used in configurations with fish, with notation used in the Results and Discussion section. NF0: No Fish; BF14: Big Fish 14 kg/m³ ; SF14: Small Fish 14 kg/m³.

\begin{tabular}{lllll}
\hline $\begin{array}{l}\text { Number of } \\
\text { fish }\end{array}$ & $\begin{array}{l}\text { Individual weight } \\
(\mathrm{g})\end{array}$ & $\begin{array}{l}\text { Total body length } \\
(\mathrm{cm})\end{array}$ & $\begin{array}{l}\text { Stocking density } \\
\left(\mathrm{kg} / \mathrm{m}^{3}\right)\end{array}$ & Notation \\
\hline 0 & - & - & 0 & NF0 \\
23 & $328.04 \pm 74.03$ & $28.50 \pm 2.4$ & 14.62 & BF14 \\
49 & $153.90 \pm 30.90$ & $22.20 \pm 1.50$ & 14.61 & SF14 \\
\hline
\end{tabular}

was not possible to take measurements at a distance less than $5 \mathrm{~cm}$ to the central pipe.

The fish were kept in a recirculation system. To ensure similar concentrations of oxygen and metabolites, the tank was supplied with two water lines. One of them was used to supply treated and oxygenated water by injection from the filtration module. The treated water line was fixed in all trials $(700 \mathrm{~L} / \mathrm{h})$ except the experiment with a flow rate of $550 \mathrm{~L} / \mathrm{h}$, where the entire flow rate was supplied by the treated line. The other water line was non-treated water and was used to achieve higher velocities (Fig. 4). In experiments without fish, water was always supplied by the non-treated line.

\subsubsection{Obtaining the velocity profiles in the tanks}

Velocity profiles were obtained measuring velocities on the $X$ and $Y$ axes ( $V_{x}$ and $V_{y}$, respectively) every $10 \mathrm{~cm}$ along the tank's diametral axis at $90^{\circ}$ from the water inlet (Fig. 5a). A total of 14 points of measurement were used (Fig. 5b).

Velocity measurements were taken with an Acoustic Doppler Velocimetry sensor (ADV) by Nortek (Nortek $10 \mathrm{MHz}$ velocimeter), with the sampling volume placed $5 \mathrm{~cm}$ below the probe. Measurements were obtained at the mid-water depth at $25 \mathrm{~Hz}$ frequency for 2 min at each point $(n=3000)$. All the measurements were made when the steady-state was reached. A detailed description of the post-processing data can be found in Masaló et al. (2008).
In order to achieve steady-state conditions in experiments without fish, we waited $5 \mathrm{~min}$ after placing the probe at each point of measurement. In experiments with fish, this interval was increased to $15 \mathrm{~min}$, as previous experiments in tanks with fish (not shown) indicated that 15 min after probe movement was enough for reaching a steady-state.

Average velocity $\left(V_{\text {avg }}\right)$ was calculated for each experiment and configuration (NF0, BF14 and SF14) according to Eq. (12), and tank resistance coefficient $\left(C_{t}\right)$ was determined using Eq. (3).

$$
V_{\text {avg }}=\frac{\sum V_{i} r_{i}}{\sum r_{i}}
$$

\subsubsection{Experimental procedure}

Velocity profiles with 9 impulse forces (including the combinations of flow rates and inlet diameters shown in Table 1) were obtained in experiments without fish (NF0) and with fish (BF14 and SF14) (Table 2). The following steps were then followed:

1) The Oca and Masaló model (2013) was applied in configurations without fish.

2) Velocity profiles and $C_{t}$ obtained in configurations with and without fish were compared.

Comparing the velocity profiles with and without fish the central forced vortex area of influence in experiments with fish was determined.

3) Velocity distributions with fish outside the central forced vortex area of influence were analyzed.

Outside the central forced vortex area of influence the Oca and Masaló model (2013) was applied and the tuning parameters obtained.

4) Velocity distributions with fish inside the central forced vortex area of influence were analyzed.

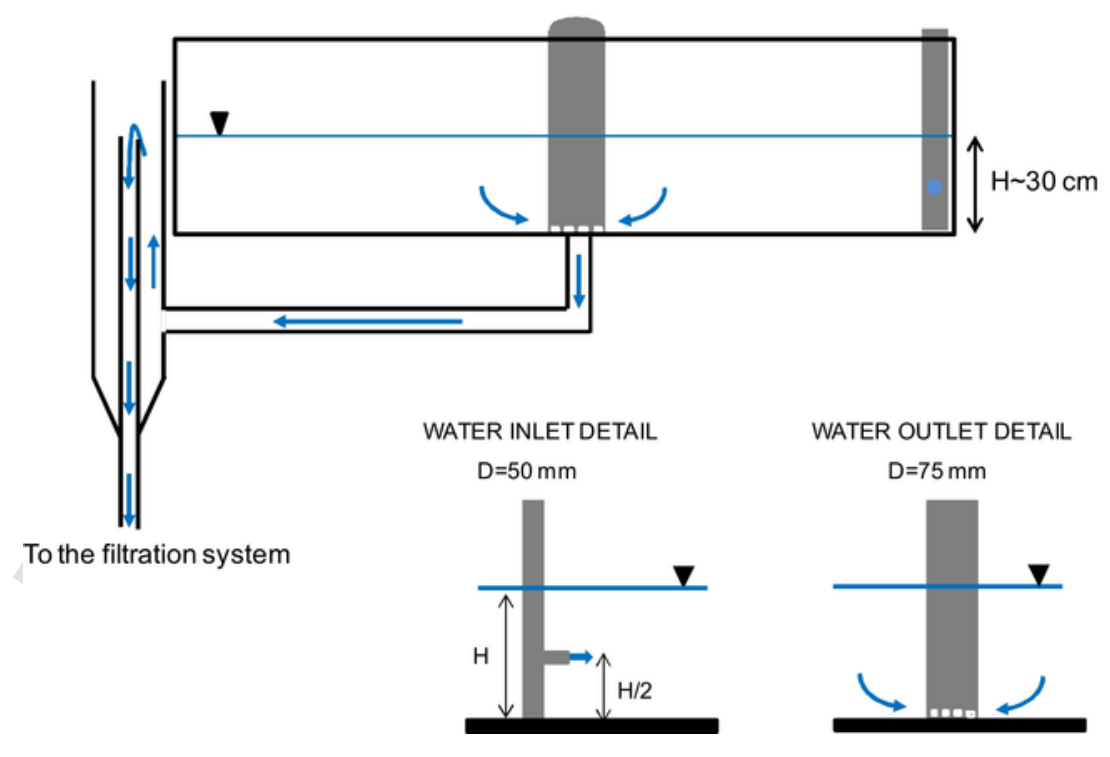

Fig. 3. Schematic diagram of the circular tank indicating water circulation, and water inlet and outlet details. 


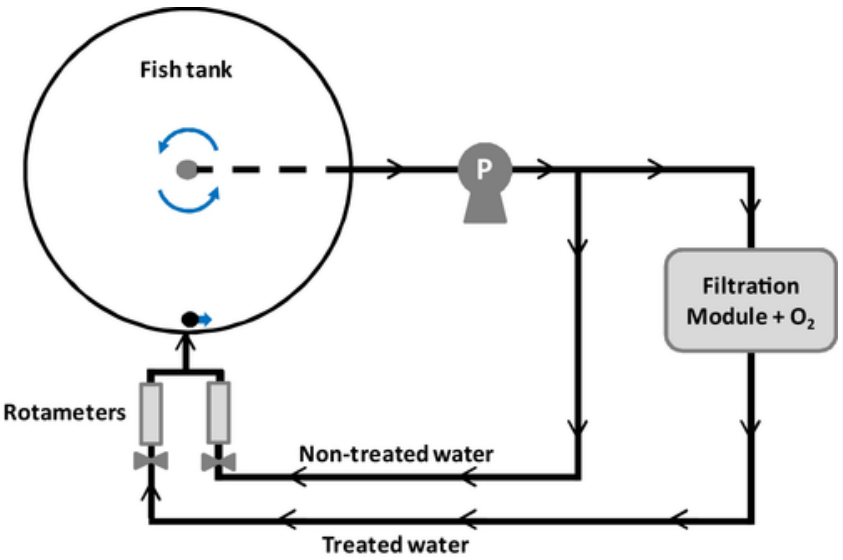

Fig. 4. Schematic diagram of the recirculating system in the laboratory. P: pump.

Inside the central forced vortex area of influence, the Burgers approximation will be tested (Eq. (11)).

5) The influence of fish on the tuning parameters of the Oca and Masaló (2013) model was evaluated, and modifications were proposed for a better description of flow around the central vortex.

6) The model was evaluated.

To compare the closeness of the modeled velocities $\left(V_{m}\right)$ and the measured velocities $\left(V_{i}\right)$, the Root Mean Square error (RMSe) was calculated according to Eq. (13).

$$
R M S_{e}=\sqrt{\frac{\sum_{i=0}^{N}\left(V_{i}-V_{m}\right)^{2}}{N}}
$$

with $N$ being the number of measurements.

(a)

(b)
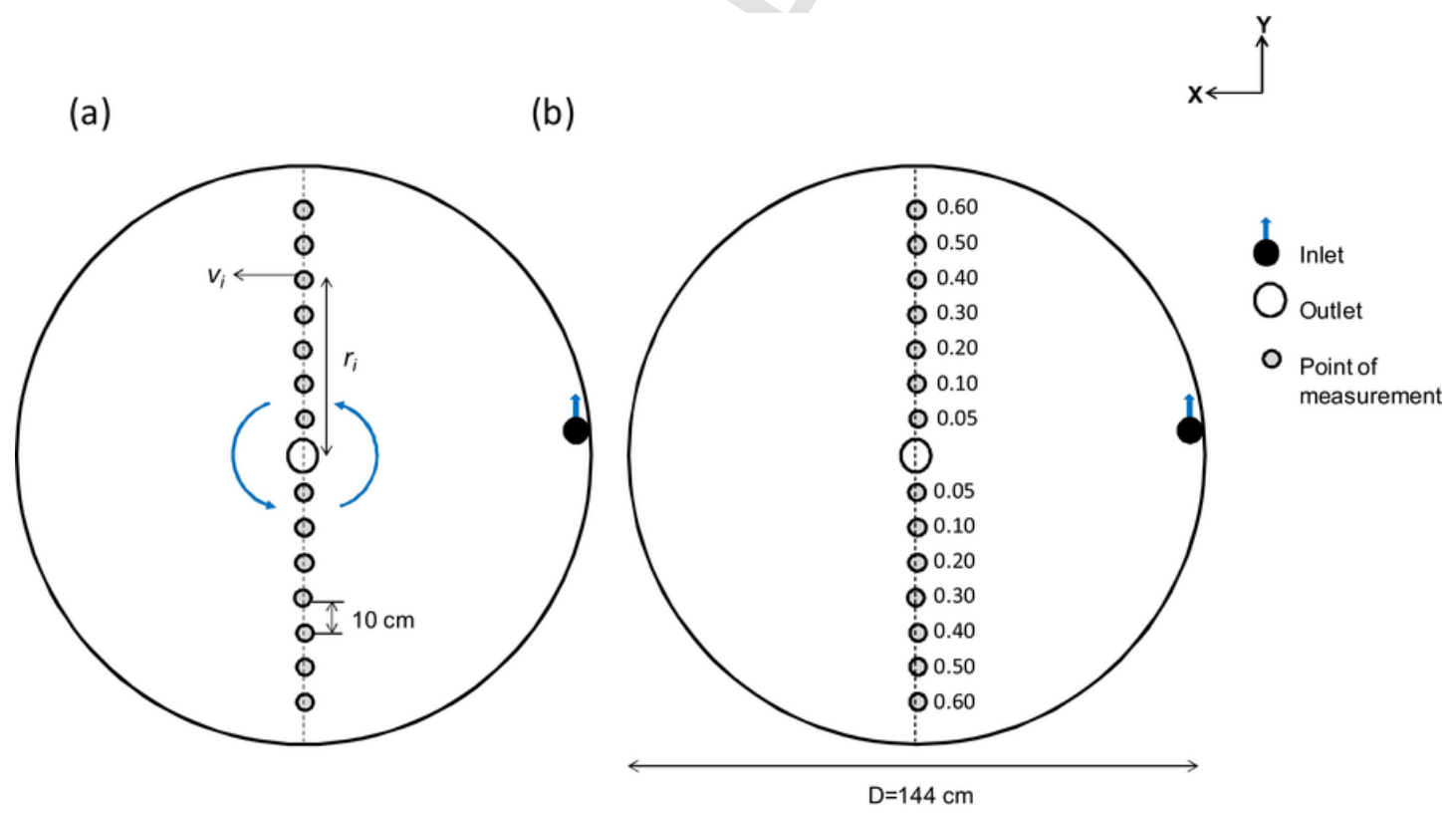

The RMSe (in $\mathrm{m} / \mathrm{s}$ ) represents the sample standard deviation of the differences between modeled values and measured values (a value of 0 indicates a perfect fit between measured and modeled velocities).

\section{Results and discussion}

\subsection{Velocity profiles in experiments without fish}

In Fig. 6, velocity profiles obtained in configurations without fish are shown. A slight asymmetry is observed between both tank radii, indicating that the center of the vortex is not at the center of the tank. This slight asymmetry must be attributed to the position of the two monitored radius relative to the water inlet jet (see Fig. 5), and the flow will be analyzed assuming identical velocity profiles for both tank radius.

In all configurations, it can be observed that velocities decrease from the wall to an intermediate radius, and they increase from this intermediate radius to the tank center. The increment toward the center of the tank is higher at higher flow rates, as Oca and Masaló (2013) observed in a previous work. Also, velocities near the wall are higher at higher $\mathrm{Fi}$.

The central forced vortex area of influence around the center of the tank cannot be observed, indicating that in experiments without fish this area is lower than the minimal distance from the measurement points to the tank center $(5 \mathrm{~cm})$.

To determine the distribution of velocities along the radius by following Eq. (8), we must obtain the angular momentum per unit mass next to the tank wall $\left(\beta_{w}\right)$ and around the central axis $\left(\beta_{0}\right)$.

From the $\beta$ distribution, $k$ is obtained by linear regression between $\log \beta_{0}$ and $r$ (Eq. (6)); and $\beta_{0}$ and $\beta_{w}$ are calculated by taking $r=0$ and $r=R$, respectively. The results are summarized in Table 3 .

\subsubsection{Relationship between $\beta_{w}$ and $F_{i} / H$}

As Oca and Masaló (2013) pointed out, in the present work the angular momentum per unit mass next to the tank wall $\left(\beta_{w}\right)$ is proportional to $\left(F_{i} / H\right)^{0.5}$ (Eq. (9)). The relationship between $\beta_{w}$ and $\left(F_{i} / H\right)^{0.5}$

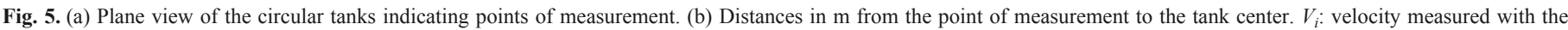
ADV probe at a radius $r_{i}$. 
Q 550-Vin 1.16-Fi 0.183

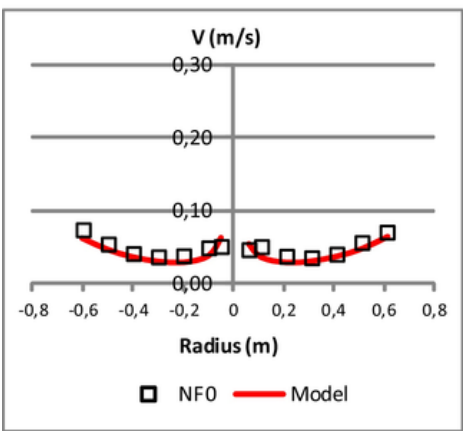

Q 1000-Vin 0.35-Fi 0.1

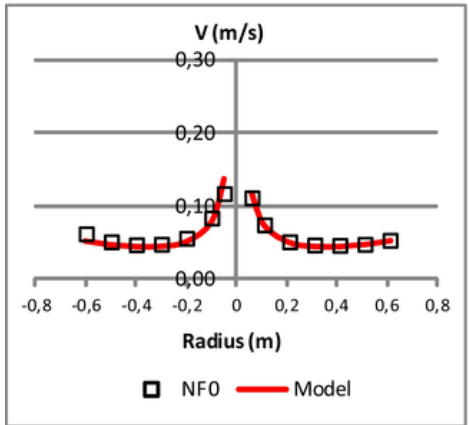

Q 1500-Vin 1.27-Fi 0.546

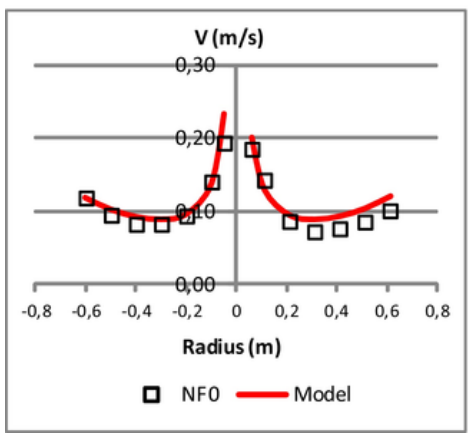

Q 800-Vin 0.68-Fi 0.156

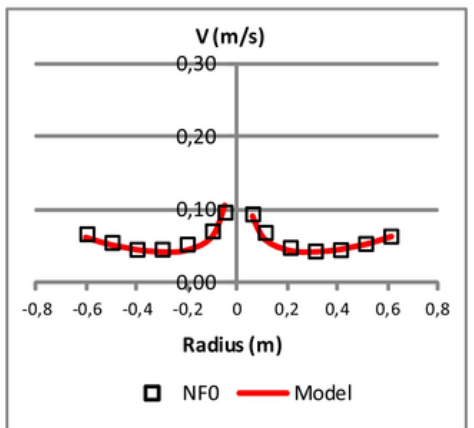

Q 1000-Vin 0.85-Fi 0.243

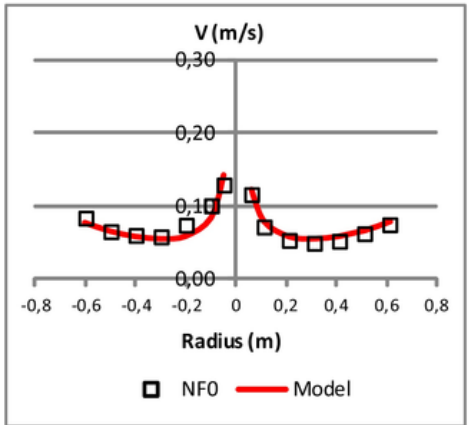

Q 1900-Vin 0.66-Fi 0.36

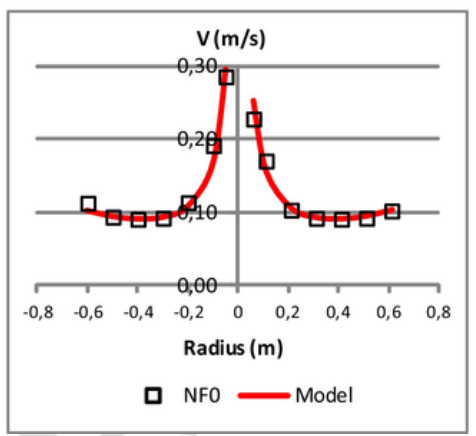

Q 800-Vin 1.68-Fi 0.387

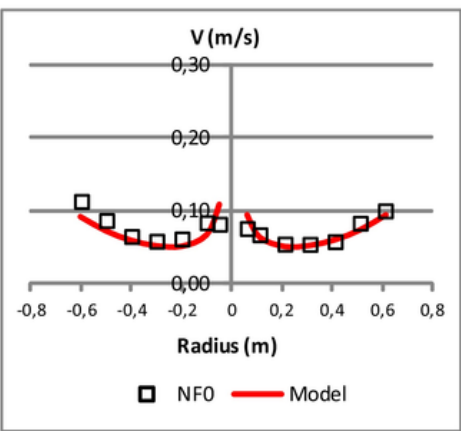

Q 1500-Vin 0.52-Fi 0.225

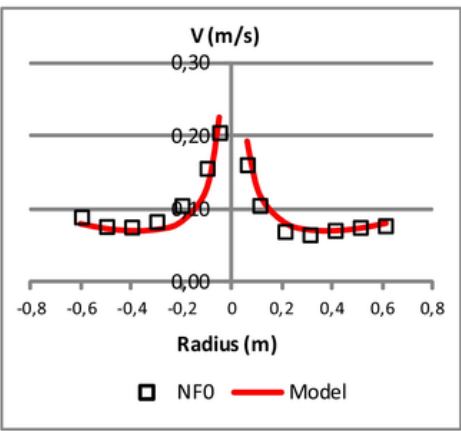

Q 1900-Vin 1.6-Fi 0.876

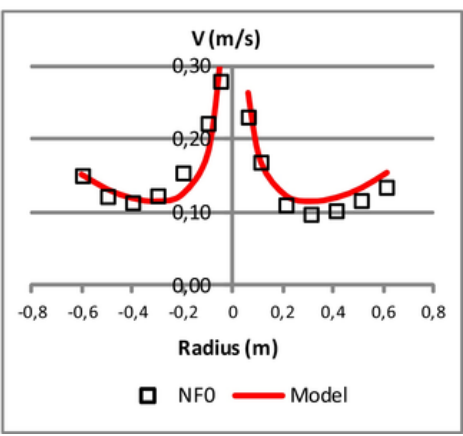

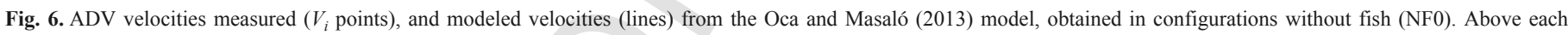
graphic are the details of flow rate $(Q$ in $\mathrm{L} / \mathrm{h})$, water inlet velocity $\left(V_{i n}\right.$ in $\left.\mathrm{m} / \mathrm{s}\right)$ and impulse force $(F i$ in $\mathrm{N})$.

Table 3

Values of $k, \beta_{0}$ and $\beta_{w}$ for each tank configuration in experiments without fish (NF0), and coefficient of determination $\mathrm{R}^{2}$ for the regression between $\beta$ and $r$.

\begin{tabular}{lllll}
\hline Tank configuration & $k\left(\mathrm{~m}^{-1}\right)$ & $\beta_{0}\left(\mathrm{~m}^{2} / \mathrm{s}\right)$ & $\beta_{w}\left(\mathrm{~m}^{2} / \mathrm{s}\right)$ & $\mathrm{R}^{2}$ \\
\hline $\mathrm{Q}=550-\mathrm{Fi}=0.183$ & 4.66 & 0.0027 & 0.0739 & 0.978 \\
$\mathrm{Q}=800-\mathrm{Fi}=0.156$ & 3.50 & 0.0048 & 0.0575 & 0.990 \\
$\mathrm{Q}=800-\mathrm{Fi}=0.387$ & 4.56 & 0.0042 & 0.1076 & 0.978 \\
$\mathrm{Q}=1000-\mathrm{Fi}=0.100$ & 2.98 & 0.0058 & 0.0479 & 0.989 \\
$\mathrm{Q}=1000-\mathrm{Fi}=0.243$ & 3.39 & 0.0060 & 0.0666 & 0.974 \\
$\mathrm{Q}=1500-\mathrm{Fi}=0.225$ & 2.80 & 0.0095 & 0.0692 & 0.950 \\
$\mathrm{Q}=1500-\mathrm{Fi}=0.546$ & 3.14 & 0.0095 & 0.0882 & 0.980 \\
$\mathrm{Q}=1900-\mathrm{Fi}=0.36$ & 2.60 & 0.0130 & 0.0828 & 0.986 \\
$\mathrm{Q}=1900-\mathrm{Fi}=0.876$ & 3.04 & 0.0134 & 0.1155 & 0.962 \\
\hline
\end{tabular}

for the experiments without fish is shown in Fig. 7. The tuning parameter $m$ from Eq. (9) takes the value $0.075 \mathrm{~m}^{2} \mathrm{~kg}^{-0.5}$

\subsubsection{Relationship between $\beta_{0}$ and $Q$}

Angular momentum per unit mass near the center of the tank can be related with outlet flow rate (Oca and Masaló, 2013) (Eq. (10)). This relation is shown in Fig. 8, and the tuning parameters $n$ and $p$ from Eq. (10) take the values $27.9 \mathrm{~m}^{-1}$ and $0.0018 \mathrm{~m}^{2} / \mathrm{s}$, respectively.

With the model tuning parameters obtained $\left(m=0.0750 \mathrm{~m}^{2} \mathrm{~kg}^{-0.5}\right.$ Fig. 7, and $n=27.86 \mathrm{~m}^{-1}$ and $p=-0.0018 \mathrm{~m}^{2} / \mathrm{s}$, Fig. 8) and Eq. (8), velocity $V$ for any radius as a function of $r, \beta_{w}$ and $\beta_{0}$ can be obtained. Fig. 6 shows the comparison between modeled velocities and velocities obtained with the ADV probe in experiments without fish. It can be observed that modeled velocities (lines in Fig. 6) and velocity obtained with the ADV probe $V_{i}$ (points in Fig. 6) fit very well.

Tuning parameters obtained in the present work are quite different from those obtained by Oca and Masaló (2013) using a tank with the same diameter (Table 4), due to the different building material (plastic 


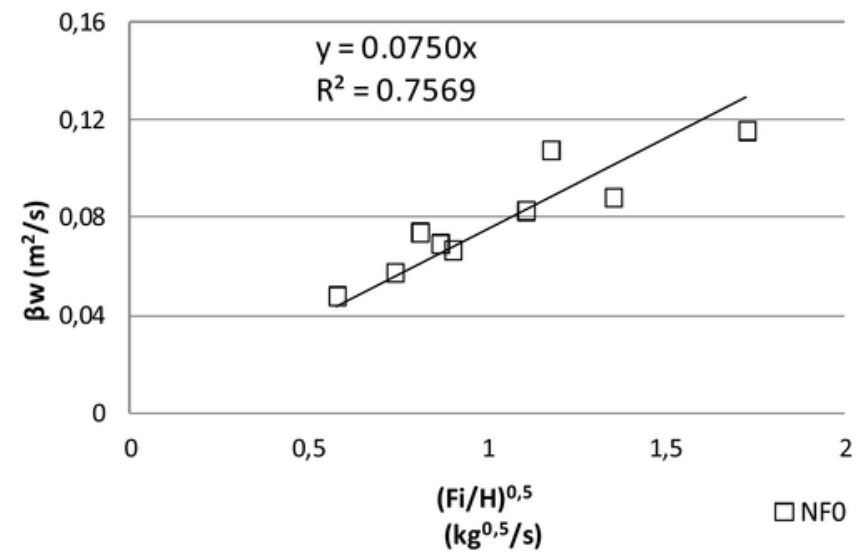

Fig. 7. Angular momentum per unit mass next to the tank wall $\left({ }_{\beta w}\right)$ versus $\left(F_{i} / H\right)^{0.5}$, obtained in experiments without fish (NF0).

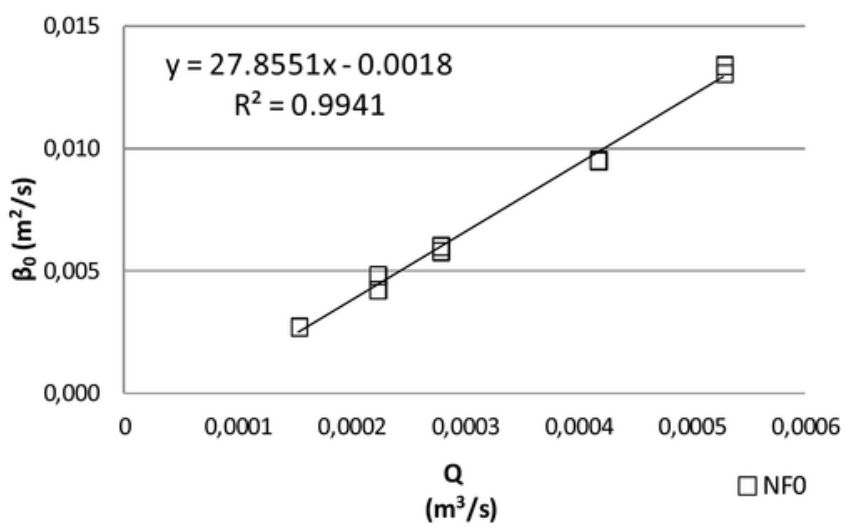

Fig. 8. Angular momentum per unit mass near the tank center $\left(_{\beta 0}\right)$ versus outlet flow rate $(Q)$, obtained in experiments without fish (NF0).

Table 4

Parameters $m$ (obtained from linear regression between $\beta_{w}$ and $F_{i}^{0.5}$, Eq. (9)), and $n$ and $p$ (obtained from linear regression between $\beta_{0}$ and $Q$, Eq. (10)) in the present work and in the Oca and Masaló (2013).

\begin{tabular}{lll}
\hline Parameter & $\begin{array}{l}\text { Present work }\left(F_{i} \text { from } 0.100 \text { to }\right. \\
0.876 \mathrm{~N})\end{array}$ & $\begin{array}{l}\text { Oca and Masaló }(2013)\left(F_{i} \text { from } 0.350\right. \\
\text { to } 1.480 \mathrm{~N})\end{array}$ \\
\hline & $\begin{array}{l}\text { Relation between } \beta_{w} \text { and }\left(F_{i} / H\right)^{0.5} \\
\text { (Eq. }(8)) \\
m\end{array}$ & 0.1115 \\
$\mathrm{R}^{2}$ & 0.0750 & 0.96 \\
& 0.76 & 34.27 \\
$n$ & Relation between $\beta_{0}$ and $Q$ (Eq. (9)) \\
$p$ & 27.86 & -0.0038 \\
$\mathrm{R}^{2}$ & -0.0018 & 0.97 \\
\hline
\end{tabular}

in 2013 and fiberglass in the present work) and different geometry of the inlet devices.

\subsection{Comparison between velocity profiles obtained in configurations with and without fish}

In Fig. 9, velocities measured along the tank diameter are shown for the experiments without fish (NF0) and with fish (BF14 and SF14). If we compare the experiments with and without fish, it can be observed that the main differences in the velocities are located near the tank center, with the velocities in this zone being much higher in experiments without fish. Near the tank wall, velocities are slightly higher in experiments without fish. The modification in the velocity profile near the outlet when there are fish in the tank can have consequences on the self-cleaning properties of the tank, since low velocities in the central area could promote biosolids settling.

These results agree with those obtained by Plew et al. (2015), who found differences in the velocity profile in a tank with fish (Atlantic salmon, Salmo salar). They found that, with fish, velocities were reduced and turbulence was increased when compared with the tank without fish. They also demonstrated that velocities were substantially reduced in the inner area of the tank.

Relating the average velocities with impulse forces (Eq. (5)), it is shown that average velocities were proportional to the square root of the impulse force in experiments with and without fish (Table 5), as was previously demonstrated in tanks without fish (Oca and Masaló, 2007). Also it is shown that tank resistance coefficients $\left(C_{t}\right.$, Eq. (3)) were higher in experiments with fish than without fish, indicating higher resistance to water circulation when there are fish in the tank. Plew et al. (2015) also found higher $C_{t}$ in experiments with fish than without fish. In the present work using similar densities but different fish sizes (BF14 and SF14), higher resistance was observed for small fish than for big fish. Plew et al. (2015) used a similar number of fish with different sizes (and, therefore, different stocking densities), and they also found higher $C_{t}$ for small fish sizes when compared with medium fish, despite the lower stocking density.

Body and fin oscillations in swimming fish promote the creation of localized jets and vortices behind them (Drücker and Lauder, 1999; Hanke et al., 2000). These shedding vortices increase the kinematic eddy viscosity and act as redistributors of momentum (Sfakiotakis et al., 1999). This fact results in a flatter profile of angular velocities $(\omega=V / r)$ that especially affect the area around the central forced vortex, which, in tanks without fish, shows higher gradients of $\omega$, as illustrated in Fig. 10. In the experiments reported here, the volume affected by this flattening of the angular velocity profile was roughly delimitated by a central cylinder with a radius of about $0.3 \mathrm{~m}$, which represents $18 \%$ of the water tank volume.

\subsection{Velocity distributions with fish outside the central forced vortex area of influence}

In experiments with fish, to determine the angular momentum per unit mass near the tank wall and around the center of the tank $\left(\beta_{w}\right.$ and $\beta_{0}$, respectively), we use only the velocity measurements taken at $r \geq 0.3 \mathrm{~m}$

Distributions of angular momentum per unit mass $(\beta)$ versus radius in experiments with fish were drawn, and $K, \beta_{0}$ and $\beta_{w}$ are calculated (Table 6).

Table 7 shows $m, n$ and $p$ values (tuning parameters) obtained for experiments with and without fish. In analyzing the relationship between $\beta_{w}$ and $\left(\left(F_{i} / H\right)^{0.5}\right)$ (Tukey, significance value of 0.05$)$, it was observed that there were no significant differences between $m$ values obtained in experiments with fish (BF14 and SF14), but differences were encountered between experiments with and without fish (Table 7). $n$ and $p$ values are also lower with fish. Nevertheless, in analyzing the relationship between $\beta_{0}$ and $Q$, no significant differences were observed between the values obtained in experiments with and without fish.

Outside the central forced vortex area of influence, angular momentum per unit mass next to the wall $\beta_{w}$ is lower in experiments with fish than without fish. The tuning parameter $m$ of the Oca and Masaló model in experiments with fish is lower than it is without fish 


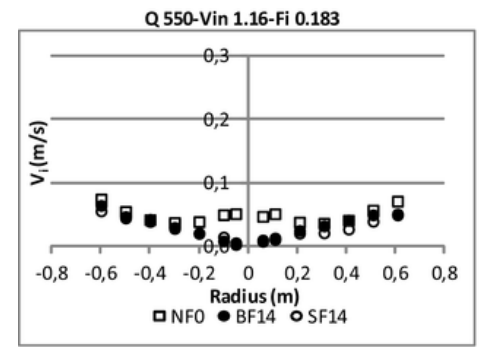

Q 1000-Vin 0.35-Fi 0.1

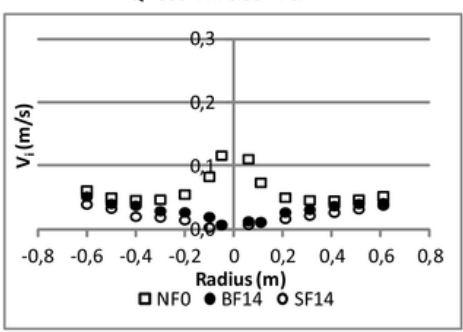

Q 1500-Vin 1.27-Fi 0.546

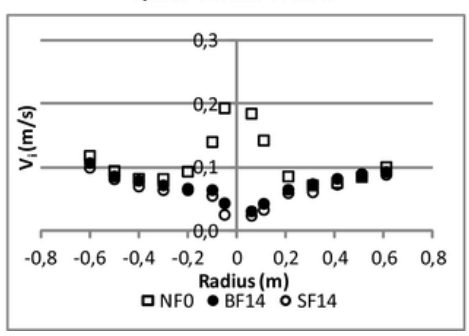

Q 800-Vin 0.68-Fi 0.156

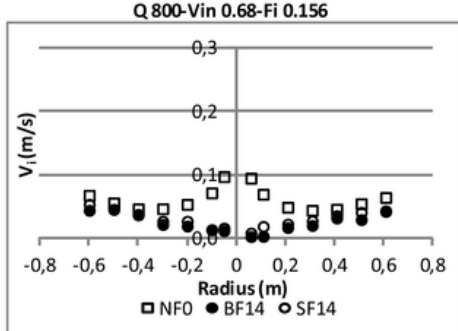

Q 1000-Vin 0.85-Fi 0.243

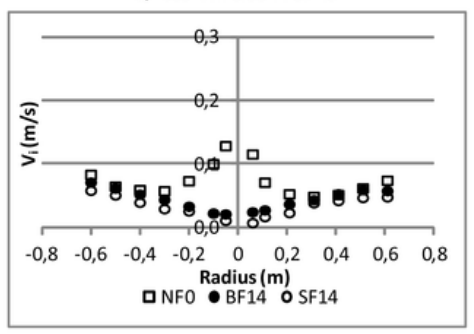

Q 1900-Vin 0.66-Fi 0.36

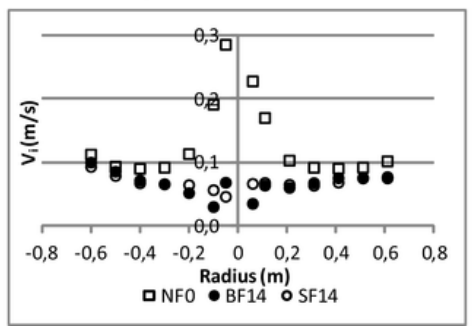

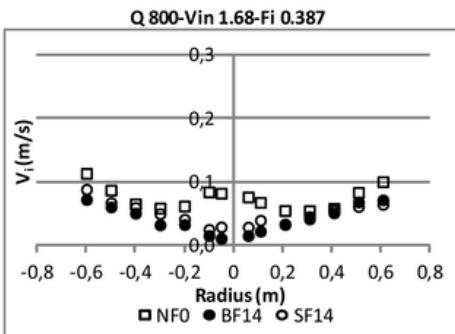

口NFO $\bullet$ BF14 OSF14

Q 1500-Vin 0.52-Fi 0.225

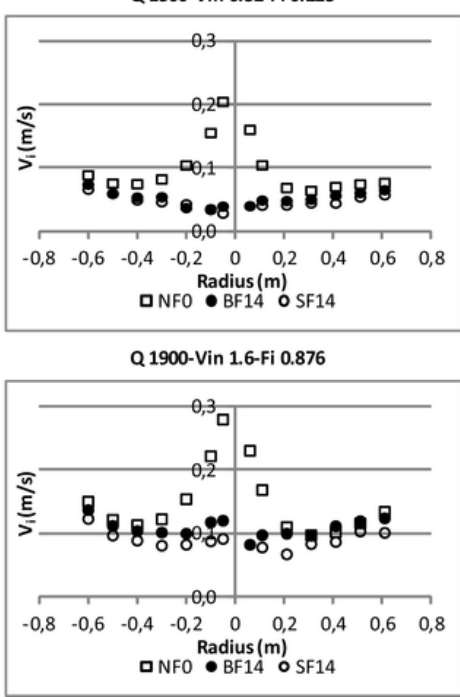

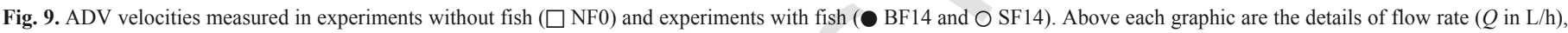
water inlet velocity $\left(V_{i n}\right.$ in $\left.\mathrm{m} / \mathrm{s}\right)$ and impulse force $(F i$ in $\mathrm{N})$.

Table 5

Relation between average velocities $\left(V_{a v g}\right)$ and $F_{i}^{0.5}(K$, Eq. (5)), coefficient of regression $\mathrm{R}^{2}$ is also shown) and tank resistance coefficient $\left(C_{t}\right.$, Eq. (3)), obtained in experiments without (NF0) and with fish (BF14 and SF14).

\begin{tabular}{llll}
\hline Parameter & NF0 & BF14 & SF14 \\
\hline$K$ & 0.1459 & 0.1163 & 0.1056 \\
$\mathrm{R}^{2}$ & 0.85 & 0.90 & 0.93 \\
$C_{t}$ & 0.0315 & 0.0495 & 0.0601 \\
\hline
\end{tabular}

(Table 7), indicating that, with a determined impulse force, velocities near the wall will be lower with fish in the tank.

\subsection{Velocity distributions inside the central forced vortex area of influence in experiments with fish}

As shown in Fig. 9, the highest differences between velocity profiles in experiments with and without fish are due to the velocities near the outlet zone. Thus, in order to model velocities in the influence area of the forced vortex $(\mathrm{r} \leq 0.3 \mathrm{~m})$, we introduce an adaptation of the Oca and Masaló (2013) model for tanks with fish and base it on Burgers' proposal for a bathtub vortex.

The Burgers proposal for bathtubs gives a more realistic description of the transition of velocities regime around the vortex core than the Rankine proposal (Fig. 2). The distribution of tangential velocities is defined by Eq. (11). The first term of Eq. (11) $(C / r)$ details the velocity profile in a bathtub outside the central forced vortex area of influence, where the profile will depend on $\beta_{w}$ and $\beta_{0}$, and thus Eq. (11) can be rewritten as Eq. (14).

$$
V=\frac{1}{r} \beta_{0}{ }^{\left(1-\frac{r}{R}\right)} \beta_{w}{ }^{\left(\frac{r}{R}\right)}\left(1-e^{-\alpha r^{2}}\right)
$$

The term $\left(1-\mathrm{e}^{-\alpha r^{2}}\right)$ will have a strong influence on the velocity determination as the tank center gets closer ( $r$ tends to 0 ), and this influence will also be higher at lower $\alpha$ values.

Alpha values $(\alpha)$ were determined for each configuration by taking the $\alpha$ value that implies, for each configuration, the minimal sum of differences (RMSe) between experimental velocities $\left(V_{i}\right)$ obtained with the ADV probe and the modeled velocities $\left(V_{m}\right)$. The $\alpha$ values obtained were then related with $F_{i}$, and it was found that a linear relation exists between $\alpha$ and $F_{i}\left(\alpha \sim F_{i}\right)$. Taking the slope of the regression between $\alpha$ and $F_{i}$ as $b, \alpha$ was calculated as $\alpha=b \times F i$. The values of $b$ encountered in the present work were 191.44 and 167.89 for experiments BF14 and SF14, respectively.

The modification of the Oca and Masaló model for tanks with fish was also applied in experiments without fish. The results showed a good fit between modeled and measured velocities (data not shown). The $b$ value in experiments without fish took the value 7510 $\left(\alpha=7510 \times F_{i}\right)$, around 40 times higher than the value obtained in tanks with fish. High $\alpha$ values imply that the term $\left(1-\mathrm{e}^{-\alpha r^{2}}\right)$ will be very close to 1 , and the modification induced by this term in the velocity profile will be circumscribed to a very small area around the outlet. 
(a)

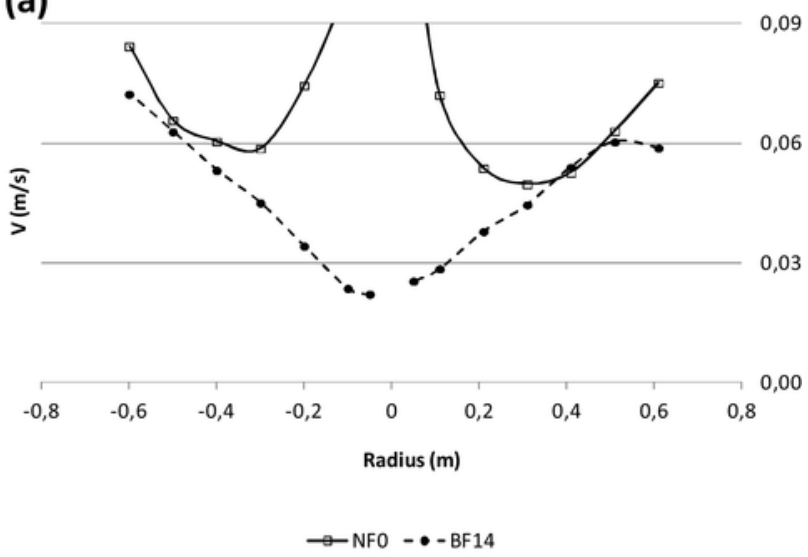

(b)

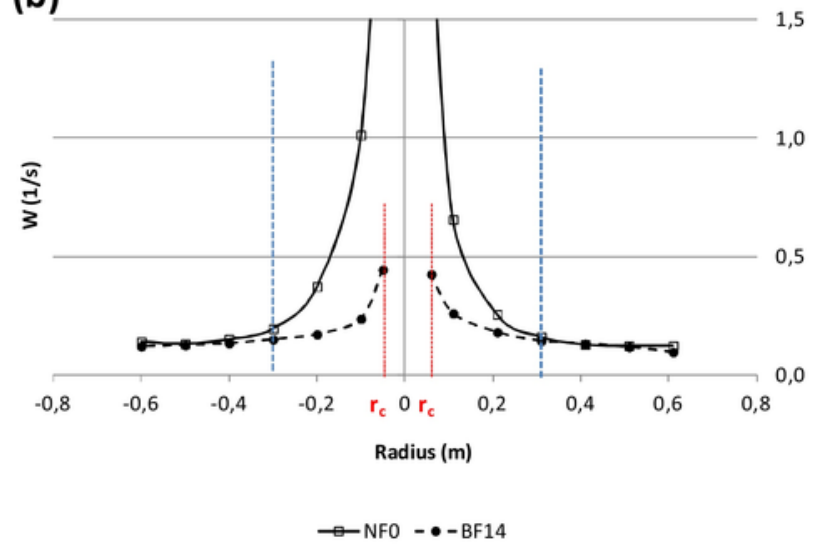

Fig. 10. (a) Tangential velocity $(V)$ and (b) angular velocity $(\omega=V / r)$ profiles obtained in experiments without fish (NF0) and in experiments with big fish (BF14) for the configuration $Q 1000-V_{i n} 0.85-F_{i} 0.243$. The dashed blue line indicates the central forced vortex area of influence considered in experiments with fish $(r=0.3 \mathrm{~m})$; the dashed red line represents the diameter occupied by the central forced vortex (not experimentally measured). (For interpretation of the references to color in this figure legend, the reader is referred to the web version of this article.)

\subsection{Comparison of measured and modeled velocities}

In Fig. 11, the velocity profiles from velocities measured in fish tanks are shown, together with the modeled profiles obtained from the Oca and Masaló model, which is based on Burgers' vortex (dashed line) proposals for a bathtub. It is observed that the model describes the velocity profile and illustrates the greater area affected by the central forced vortex when compared with a tank without fish.

The model evaluation included the RMSe calculation according to Eq. (13). This parameter was calculated in order to quantify differences between measured and modeled velocities. Table 8 includes the $R M S e$ calculated for each experiment, and the standard deviation of the RMSe (in each experiment, all RMSe from the 9 different configurations were averaged).

RMSe were calculated by taking into account the measured and modeled velocities along the tank diameter $(0<r<R)$, as well as inside $(r \leq 0.3 \mathrm{~m})$ and outside the central forced vortex area of influence $(r \geq 0.3 \mathrm{~m})$. It should be noted that the central forced vortex area of influence in experiments with fish $(r \leq 0.3 \mathrm{~m})$ represents only $18 \%$ of the tank volume.
Table 6

Values of $k, \beta_{0}$ and $\beta_{w}$ for each tank configuration in experiments with fish (BF14 and SF14), and the coefficient of determination $\mathrm{R}^{2}$ for the linear regression between $\beta$ and $r$. Only the velocities measured at $r \geq 0.3 \mathrm{~m}$ were considered.

\begin{tabular}{lllll}
\hline Tank configuration & $\mathrm{k}\left(\mathrm{m}^{-1}\right)$ & $\beta_{0} \mathrm{~m}^{2} / s$ & $\beta_{w} \mathrm{~m}^{2} / s$ & $\mathrm{R}^{2}$ \\
\hline & $\mathrm{BF} 14$ & & & \\
$\mathrm{Q}=550-\mathrm{Fi}=0.183$ & 4.24 & 0.0028 & 0.0570 & 0.962 \\
$\mathrm{Q}=800-\mathrm{Fi}=0.156$ & 4.43 & 0.0019 & 0.0451 & 0.891 \\
$\mathrm{Q}=800-\mathrm{Fi}=0.387$ & 4.27 & 0.0031 & 0.0636 & 0.961 \\
$\mathrm{Q}=1000-\mathrm{Fi}=0.100$ & 3.60 & 0.0034 & 0.0436 & 0.964 \\
$\mathrm{Q}=1000-\mathrm{Fi}=0.243$ & 3.53 & 0.0049 & 0.0604 & 0.960 \\
$\mathrm{Q}=1500-\mathrm{Fi}=0.225$ & 3.19 & 0.0062 & 0.0598 & 0.987 \\
$\mathrm{Q}=1500-\mathrm{Fi}=0.546$ & 3.29 & 0.0084 & 0.0872 & 0.985 \\
$\mathrm{Q}=1900-\mathrm{Fi}=0.36$ & 3.16 & 0.0081 & 0.0764 & 0.949 \\
$\mathrm{Q}=1900-\mathrm{Fi}=0.876$ & 3.16 & 0.0118 & 0.1119 & 0.986 \\
& $\mathrm{SF} 14$ & & & \\
$\mathrm{Q}=550-\mathrm{Fi}=0.183$ & 4.74 & 0.0019 & 0.0541 & 0.937 \\
$\mathrm{Q}=800-\mathrm{Fi}=0.156$ & 4.12 & 0.0026 & 0.0484 & 0.954 \\
$\mathrm{Q}=800-\mathrm{Fi}=0.387$ & 3.74 & 0.0049 & 0.0693 & 0.945 \\
$\mathrm{Q}=1000-\mathrm{Fi}=0.100$ & 4.41 & 0.0017 & 0.0398 & 0.974 \\
$\mathrm{Q}=1000-\mathrm{Fi}=0.243$ & 3.77 & 0.0035 & 0.0513 & 0.944 \\
$\mathrm{Q}=1500-\mathrm{Fi}=0.225$ & 3.34 & 0.0051 & 0.0553 & 0.970 \\
$\mathrm{Q}=1500-\mathrm{Fi}=0.546$ & 3.62 & 0.0066 & 0.0865 & 0.986 \\
$\mathrm{Q}=1900-\mathrm{Fi}=0.36$ & 3.15 & 0.0078 & 0.0725 & 0.969 \\
$\mathrm{Q}=1900-\mathrm{Fi}=0.876$ & 3.30 & 0.0094 & 0.0980 & 0.976 \\
\hline
\end{tabular}

Table 7

Parameters $m$ (obtained from linear regression between $\beta_{w}$ and $F_{i}^{0.5}$, Eq. (8)), and $n$ and $p$ (obtained from linear regression between $\beta_{0}$ and $Q$, Eq. (9)) in experiments BF14 and SF14. Results in experiments without fish (NF0) are also shown. Different superscript indicates statistically significant differences at the 0.05 level (Tukey).

\begin{tabular}{llll}
\hline Parameter & NF0 & BF14 & SF14 \\
\hline & Relation between $\beta_{w}$ and $F_{i}^{0.5}($ Eq. (8)) & \\
$m$ & $0.0750^{\mathrm{a}}$ & $0.0649^{\mathrm{b}}$ & $0.0614^{\mathrm{b}}$ \\
$R^{2}$ & 0.76 & 0.93 & 0.94 \\
& Relation between $\beta_{0}$ and $Q($ Eq. (9)) & \\
$n$ & $27.86^{\mathrm{a}}$ & $27.37^{\mathrm{a}}$ & $23.62^{\mathrm{a}}$ \\
$p$ & -0.0018 & -0.0017 & -0.0010 \\
$\mathrm{R}^{2}$ & 0.99 & 0.84 & 0.8 \\
\hline
\end{tabular}

Results showed that in experiments both with and without fish, higher RMSe were observed in the area near the tank center $(r \leq 0.3 \mathrm{~m})$.

\section{Conclusions}

This work analyses the differences observed in average velocities and the velocity profile in a circular tank ( $1.44 \mathrm{~m}$ diameter) without fish and with fish of different sizes at a density of $14 \mathrm{~kg} / \mathrm{m}^{3}$.

Average velocities obtained in tanks with swimming fish were lower than those obtained with identical impulse force and flow rate in a tank without fish. The decrease in average velocity implied a higher tank resistance coefficient $\left(C_{t}\right)$, indicating an increase in water resistance to flow with fish. Also it was observed that average velocities in a circular tank with fish were proportional to the square root of the impulse force, as had been demonstrated by Oca and Masaló (2013) in a tank without fish.

Differences in average velocities are a consequence of the differences observed in the velocity profile in experiments with and without fish. It was demonstrated that the main differences in the velocity profile occurred in the area near the tank outlet, where velocities were much lower in experiments with fish. Velocities near the tank walls 


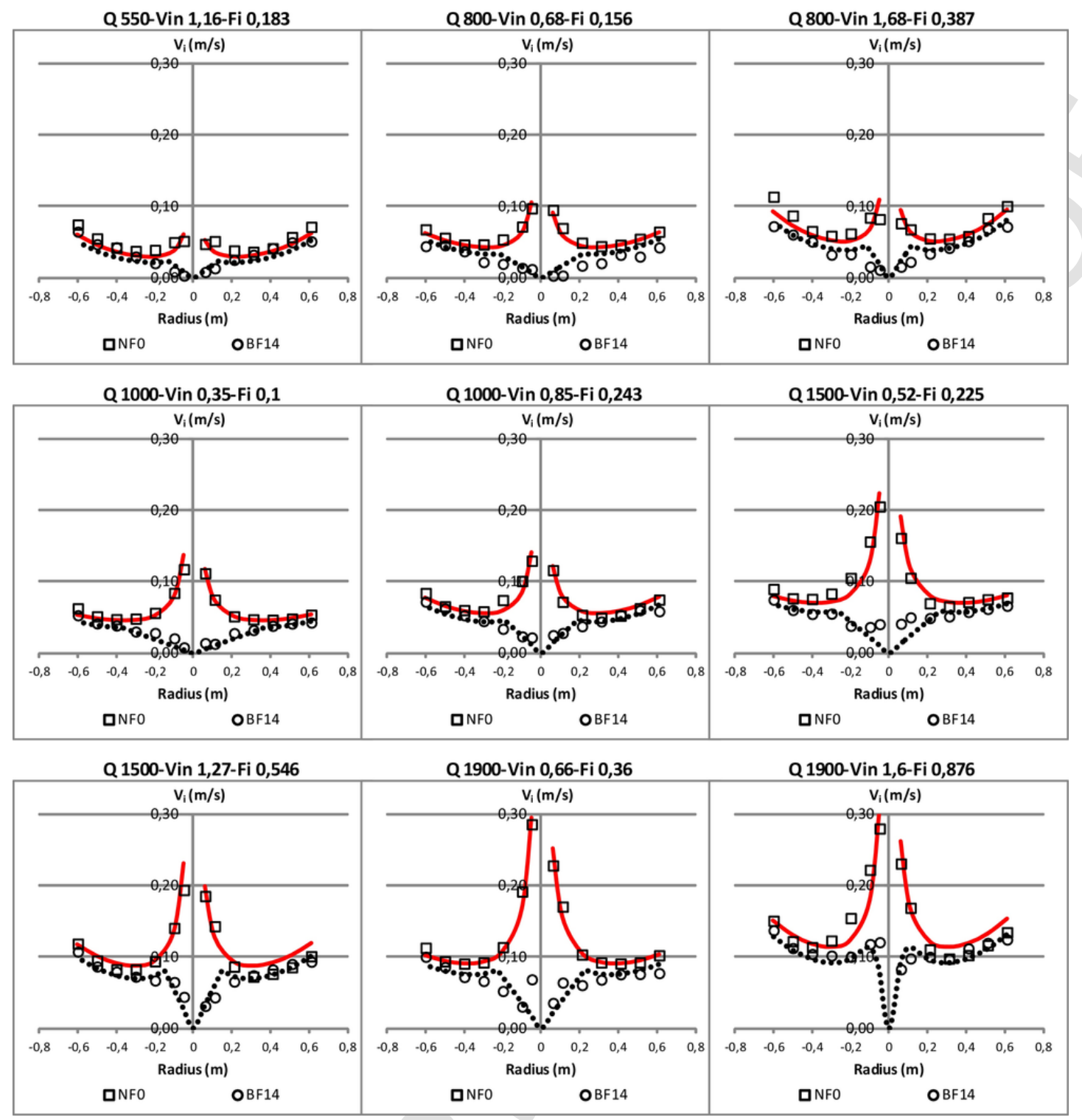

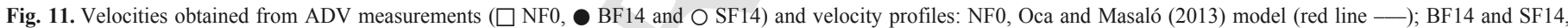

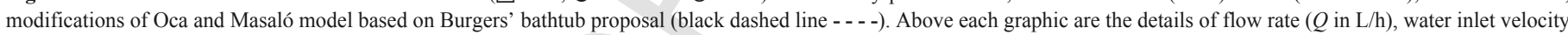
$\left(V_{\text {in }}\right.$ in $\left.\mathrm{m} / \mathrm{s}\right)$ and impulse force $\left(F_{i}\right.$ in $\left.\mathrm{N}\right)$. (For interpretation of the references to color in this figure legend, the reader is referred to the web version of this article.)

were also lower in tanks with fish, but differences were scarce. Experiments with big (approx. $330 \mathrm{~g}$ ) and small (approx. $154 \mathrm{~g}$ ) fish did not present greater differences in velocity profiles.

The lower velocities in the central area of the tank with fish can be conferred to the turbulence introduced by swimming fish, which increase the kinematic eddy viscosity and thus generate a flattening of the angular velocity profile in the central area of the tank. This is noticeable in a radius of about $0.3 \mathrm{~m}$ ( $18 \%$ of the total volume of the tank).

This work proposes some improvements to include in the current available model (Oca and Masaló, 2013) in order to have a faithful prediction of flow patterns in circular fish rearing tanks, especially when modeling the velocities near the central area of the tank. The proposal combines the Oca and Masaló model with Burgers' pro- posal for a bathtub vortex. The velocity profile obtained with the Oca and Masaló model was multiplied by $\left(1-\mathrm{e}^{-\alpha r^{2}}\right)$, and the parameter $\alpha$ in Burgers' proposal is experimentally determined in experiments with and without fish, with its value being nearly proportional to the impulse force of each tank configuration. It must be observed that the lower the $\alpha$ value, the higher the effect on velocities in the central area of the tank. The $\alpha$ value obtained in experiments without fish was about forty times higher than in experiments with fish.

\section{Acknowledgement}

This work was funded by Spanish Ministerio de Educación y Ciencia (AGL2009-1655). 


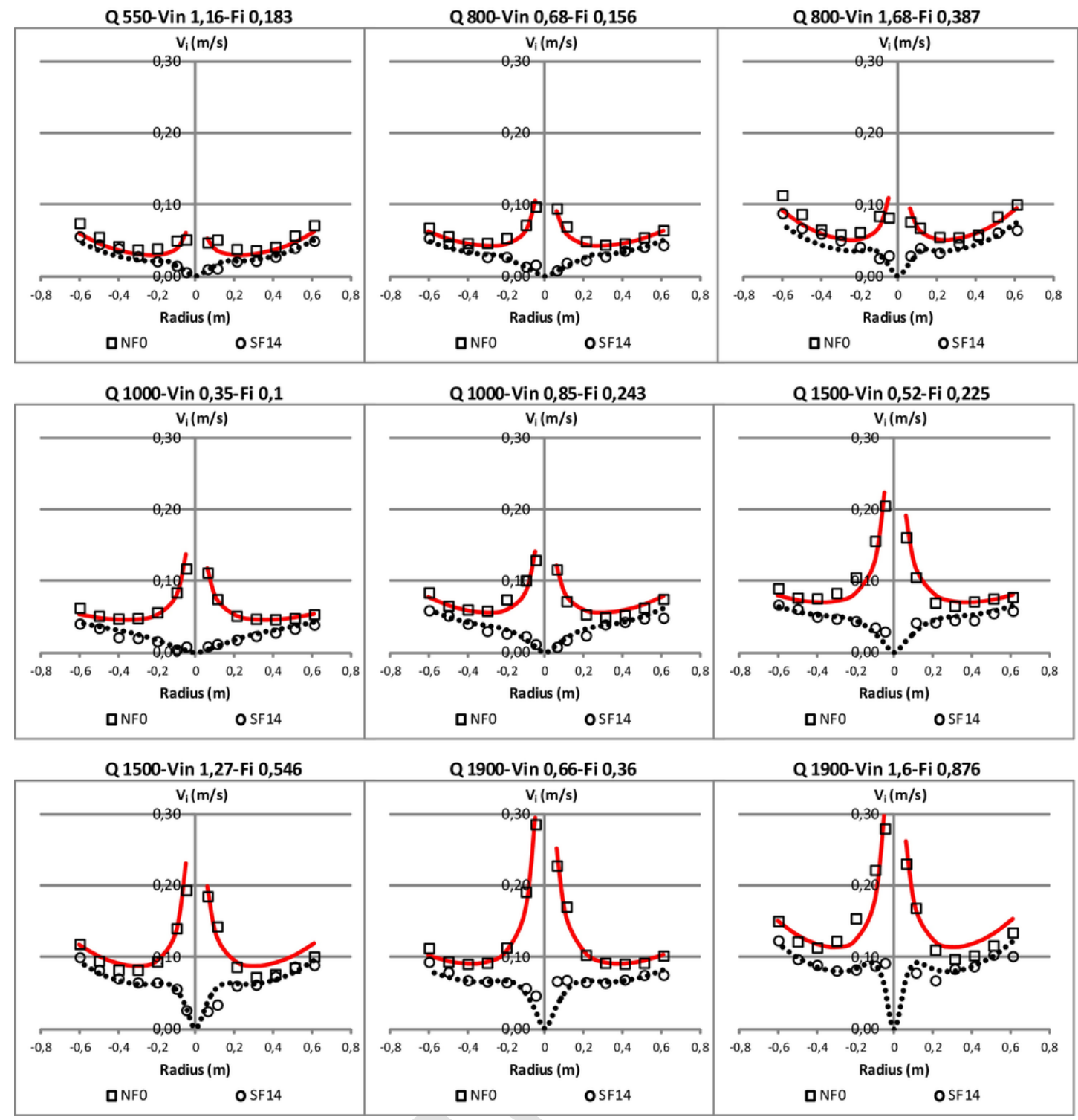

Fig. 11. (Continued)

Table 8

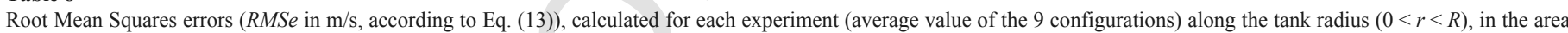
$r \geq 0.3 \mathrm{~m}$, and in the central forced vortex area of influence considered for $r \leq 0.3 \mathrm{~m}$.

\begin{tabular}{|c|c|c|c|c|c|c|c|c|c|}
\hline & NF0 & & & BF14 & & & SF14 & & \\
\hline & $0>r>R$ & $r \leq 0,3 \mathrm{~m}$ & $r \geq 0,3 \mathrm{~m}$ & $0>r>R$ & $r \leq 0,3 \mathrm{~m}$ & $r \geq 0,3 \mathrm{~m}$ & $0>r>R$ & $r \leq 0,3 \mathrm{~m}$ & $r \geq 0,3 \mathrm{~m}$ \\
\hline Average & 0.0110 & 0.0129 & 0.0072 & 0.0094 & 0.0104 & 0.0067 & 0.0096 & 0.0109 & 0.0064 \\
\hline Std & 0.0052 & 0.0065 & 0.0038 & 0.0039 & 0.0057 & 0.0024 & 0.0054 & 0.0075 & 0.0020 \\
\hline
\end{tabular}

\section{References}

Andersen, A.P., Bohr, T., Stenum, B., Juul Rasmussen, J., Lautrup, B., 2006. The bathtub vortex in a rotating container. J. Fluid Mech. 556, 121-146.

Burgers, J.M., 1948. A mathematical model illustrating the theory of turbulence. Adv. Appl. Mech. 1, 197-199.

Burley, R., Klapsis, A., 1985. Flow distribution studies in fish rearing tanks. Part 2. Analysis of hydraulic performance of $1 \mathrm{~m}$ square tanks. Aquacult.

Eng. 4, 113-134.
Drücker, E.G., Lauder, G.V., 1999. Locomotor forces on a swimming fish: three-dimensional vortex wake dynamics quantified using Digital Particle Image Velocimetry. J. Exp. Biol. 202, 2393-2412.

Hanke, W., Brücker, C., Bleckmann, H., 2000. The ageing of the low-frequency water by disturbances caused by swimming goldfish and its possible relevance to prey detection. J. Exp. Biol. 203, 1193-1200.

Klapsis, A., Burley, R., 1984. Flow distribution studies in fish rearing tanks. Part 1. Design constraints. Aquacult. Eng. 3, 103-118.

Larmoyeux, J.D., Piper, R.G., Chenoweth, H.H., 1973. Evaluation of circular tanks for salmonid production. Progress. Fish Culturist 35, 122-131. 
Lunger, A., Rasmussen, M.R., Laursen, J., McLean, E., 2006. Fish stocking density impacts tank hydrodynamics. Aquaculture 254, 370-375.

Masaló, I., Reig, L., Oca, J., 2008. Study of fish swimming activity using Acoustical Doppler Velocimetry (ADV) techniques. Aquacult. Eng. 38, 43-51.

Oca, J., Masaló, I., 2007. Design criteria for rotating flow cells in rectangular aquaculture tanks. Aquacult. Eng. 36, 36-44.

Oca, J., Masaló, I., 2013. Flow pattern in aquaculture circular tanks: influence of flow rate, water depth and water inlet \& outlet features. Aquacult. Eng. 52, 65-72.

Oca, J., Masaló, I., Reig, L., 2004. Comparative analysis of flow patterns in aquaculture rectangular tanks with different water inlet characteristics. Aquacult. Eng. 31, 221-236.

Plew, D.R., Klebert, P., Rosten, T.W., Aspaas, S., Birkevold, J., 2015. Changes to flow and turbulence caused by different concentrations of fish in a circular tank. J. Hydraulic Res. 53, 364-383.
Rankine, W.J.M., 1858. In: Millar, W.J. (Ed.), A Manual of Applied Mechanics, 2nd edition Charles Griffin \& Co., London.

Rasmussen, M.R., Laursen, J., Craig, S.R., McLean, E., 2005. Do fish enhance tank mixing. Aquaculture 250, 162-174.

Sfakiotakis, M., Lane, D.M., Davies, J.B.C., 1999. Review of fish swimming modes for aquatic locomotion. IEEE J. Oceanic Eng. 24, 237-252.

Tvinnereim, K., Skybakmoen, S., 1989. Water exchange and self-cleaning in fish-rearing tanks. Aquacult. A: Biotechnol. Progress

Tvinnereim, K., 1988. Design of water inlets for closed fish farms. Aquaculture Engineering Technologies for the Future. The Institution of Chemical Engineers Symposium Serie $\mathrm{N}^{\circ}$ 111. EFCE Publication $\mathrm{N}^{\circ}$ 66. pp 241-249.

Yukimoto, S., Niino, H., Noguchi, T., Kimura, R., Moulin, F.Y., 2010. Structure of a bathtub vortex: importance of the bottom boundary layer. Theor. Comput. Fluid Dyn. 24, 323-327. 